\title{
Sobre a Teoria da Suppositio de Guilherme de Ockham (As Marcas de uma Proposição)
}

\author{
Eligia Hirano Tunis Martins (Bolsista PIBIC/CNPq)
}

Orientador: José Carlos Estevão

O presente trabalho constitui-se de um comentário acerca e pelo que supõe a proposição: "A Física é a ciência das proposições cujos termos supõem pelas coisas naturais" Num primeiro momento, as perguntas: Por que "a física é a ciência das proposições"? Qual o significado de "proposições cujos termos supõem" ou o que se entende quando se diz "que supõe pelas coisas naturais"? ou o que supõe "coisas naturais"? parecem estar longe de serem respondidas. Entretanto, são elas respondíveis e tem por base a leitura do "Prólogo da Exposição dos Oito Livros da Física" por Guilherme de Ockham, que trata da "Noção do Conhecimento ou Ciência"

Mais precisamente, neste texto ele se ocupa primeiro, em dar ao termo ciência "as várias acepções e que não se subordinam uma às outras" 1 ; segundo, deduz certas conclusões a partir do que se diz à respeito da ciência; e, por último, discorre sobre a ciência natural, ou seja, a física. Retomando, para justificar o que foi proposto, farei uma passagem pelo texto citado até atingir a última parte quando, então, Ockham conclui que a ciência, no caso a física, supõe pelas coisas naturais e que ela é constituída de proposições.

Logo de início, Guilherme diz que "a ciência é uma qualidade existente na alma"; e, ainda, é um hábito formado a partir do movimento de muitos atos de saber. Com isto, passa-se a entender o que antes não era entendido; logo, a carência desta alguma coisa é agora suprida. Portanto este algo novo, que não tinha existência na alma e que, ora, se dá pelo hábito, é o que corresponde a qualidade, e completa ele, que deve ser um ato de intelecção ou de volição. Se a mudança se dá na alma, ou seja, se o que não era conhecido torna-se conhecido, isto significa que a alma tem agora algo que não tinha. Este algo novo na alma, se trata de um hábito e sendo assim uma qualidade, a qual se trata de intelecção ou de volicção. Se a volição é a qualidade e assim também o é a intelecção, logo o hábito da ciência é tal qualidade na alma. Isto prova a definição dada por ele: "ciência é uma qualidade existente na alma".

Para esta ciência, considera, ele, seis acepções. A saber: primeiro, "a ciência é certo conhecimento de alguma verdade" Tomamos por verdadeiro algo que não é evidentemente conhecido, mas por uma crença ou fé torna-se, conseqüentemente, evidente e dizemos conhecer. Por exemplo: "saber que Roma é uma grande cidade" embora nunca a tenha visto; o mesmo ocorre ao dizer que "este é meu pai e esta minha mãe". Portanto, tomamos por certo dados não evidentemente conhecidos.

Como segunda acepção, ciência é o "conhecimento evidente". Sabemos não ape- 
nas pelo depoimento de outros, mas também pela certeza mediata ou imediata dos termos* Desta forma, sei que a parede é branca, por perceber a sua brancura, embora não me seja dito. Encaixam-se neste caso, as verdades necessárias em como as contingentes. Por outro lado, numa outra acepção, não se concebe na ciência as coisas contingentes, importando a ela apenas os princípios e as conclusões resultantes das coisas evidentes. Nesta terceira acepção, a ciência "significa conhecimento evidente de alguma coisa necessária"s

Apresenta como quarta acepção, "o conhecimento evidente de uma verdade necessária resultante de premissas evidentes e necessárias utilizadas em raciocínios silogísticos" Por esta inferência, a ciência está relacionada às deduções pelo silogismo, e como tal, se distingue do hábito dos princípios e da sabedoria.

Em um quinto sentido, ciência é o conhecimento evidente da conclusão ou da demonstração.

$\mathrm{E}$, segundo a última acepção, ciência é empregada, às vezes "por um hábito numericamente, sem incluir hábitos especificamente distintos, mas outras vezes pela coleção de muitos hábitos com uma ordem determinada e certa" Assim, o Filósofo usa o termo ciência neste último sentido de coleção de hábitos, ou seja, um conjunto de conhecimentos dispostos em uma "ordem determinada e certa" É desta forma que a metafísica, a filosofia natural se dizem ciências, levando-se em consideração

cito Ockham - "o hábito dos princípios e das conclusões, o conhecimento dos termos, a refutação dos falsos argumentos e a solução deles"4

Deste contexto, Ockham extrai algumas conclusões, que dizem respeito à unidade, as causas, ao sujeito e ao objeto da ciência.

Começa considerando o fato de que "a metafísica, a matemática e a filosofia natural não constituem numericamente uma ciência" 5 Não existe apenas uma conclusão e não existe um relacionamento entre as proposições de forma que de uma decorra a outra, ou seja, se uma for falsa implica também na falsidade da outra e vice-versa. Reconhece, portanto, a distinção numérica das conclusões, de maneira que o erro de uma não contraria a outra conseqüência. Por exemplo: o fato de alguém possuir um hábito científico lhe permite provar a verdade em relação a este hábito científico, mas ao mesmo tempo pode ignorar outros hábitos, o que evidencia que um hábito apenas é insuficiente para provar o conjunto de uma ciência. Sendo assim, uma ciência não subsiste por ser um hábito numericamente uno, ao contrário, sua unidade é dada pelo coletivo, da mesma forma como se supõe o termo cidade, povo, exército, reino, etc., os quais compõem um conjunto de indivíduos, uma unidade coletiva.

Como segunda conclusão, enuncia ele duas causas da ciência: a final e a eficiente. Ora, se a ciência é uma "qualidade existente na alma" conforme foi explicado acima e sendo esta qualidade um acidente, logo não se pode falar em causa material e causa formal, levando-se em consideração que o acidente não tem matéria. Esta não pode ser a causa da coisa na qual ela constitui. Portanto, considera que a ciência possui apenas estas duas causas: a eficiente e a final.

Outra impropriedade é atribuir somente um "sujeito" à ciência. Ao contrário, sendo ela una por uma unidade de coleção, apresenta diversos "sujeitos" pois uma ciência concebe verdades diferentes; isto posto, a ciência não possui um só "sujeito" A 
palavra "sujeito", aqui, equivale a "subjecto" em sentido lato, é aquilo do qual se sabe alguma coisa.

Registra notável diferença entre o sujeito e o objeto. Por sujeito entende-se uma parte da proposição, ou seja, o próprio termo sujeito e por objeto da ciência considera-se toda a proposição conhecida. Disso resulta que não há um sujeito do todo, mas diversos sujeitos das diversas partes da ciência; assim como "não há o rei do mundo, mas um é rei de um país e outro de outro"6 Desta forma, quando alguns opositores exibem a ciência com apenas um sujeito, Ockham refuta-os dizendo que não só não há um sujeito, mas vários, como também não se pode afirmar que existe o sujeito primeiro da ciência. Às vezes um se distingue por um lado e às vezes outro, por outro.

Do mesmo modo, Ockham considera que não é verdade que uma ciência apresente um único objeto. Isto significa, que para ele, não é possível por exemplo perguntar qual é o objeto da filosofia da natureza. Na verdade, cada parte de uma ciência possui os seus respectivos objetos, que Ihes são próprios. Desta forma, não existe um objeto primário e que contenha ele todas as conclusões, contrariamente, um objeto assim como uma conclusão dizem respeito a um único hábito. Por exemplo: na proposição "Todo homem é educável" a proposição toda será o objeto da ciência, enquanto o sujeito da ciência é o termo "homem"

Chega, por fim, às considerações sobre a ciência natural: com o que se ocupa, como evidencia as diferenças em relação às outras ciências, e onde é ela inserida na filosofia.

De início, aponta a ocupação da filosofia natural voltada para as "substâncias sensíveis e compostas de matéria e forma" Acontece que a ciência diz respeito a um complexo ou incomplexos* ${ }^{*}$, e estes complexos não são constituídos por coisas sensíveis, nem por substâncias, mas por "intenções da alma"*; logo, a ciência natural trata das intenções da alma. Isto posto, quando Aristóteles segundo Ockham diz que a ciência não trata das coisas singulares, mas somente dos universais, Ockham explica que as coisas singulares não se referem às coisas sensiveis existentes. Portanto, para ele, a ciência não diz respeito aos singulares, ao contrário se ocupa dos universais que supõem* pelos próprios singulares.

Sendo assim, se a ciência é formada de proposições e os termos destas supõem pelas coisas naturais, termos, estes, que estão naturalmente na nossa mente, ou seja, supõem pelas realidades concretas (ex: todo fogo) e individuais, que ganham existência na mente, logo são as suposições naturais da coisas e não a coisa, que trata a ciência. Portanto, as coisas não podem ser o objeto da ciência. Para Ockham, então, os termos de uma proposição que supõe pelas coisas constitui o sujeito da ciência e a proposição, o objeto desta. Por isso, na proposição "todo fogo aquece" o objeto da ciência não é "fogo" ou a coisa que supõe por este termo, mas sim "uma intenção comum a todo fogo" ${ }^{\prime}$ logo a ciência real não trata das coisas, e sendo a filosofia uma ciência real versa sobre as intenções que supõem pelas coisas.

Por outro lado, a lógica, ou as ciências racionais se distinguem das reais pelo fato de os termos de suas proposições estarem no lugar de outros termos e não de coisas. Entretanto, conforme Ockham, "a arte ensinada pelo Filósofo, é a distinção das proposições" Tanto a lógica, ciência racional que tem por objeto os termos, as pro- 
posições e silogismos, quanto as ciências reais que tem por objeto seres dotados de existência se valem da suppositio, ou seja, tem um significado, supõe por alguma coisa.

Portanto, as diversas ciências sendo compostas de proposições, "garantem o contato direto com a realidade através dos termos das proposições que são usadas segundo a suposição pessoal" " Assim, em relação à suposição pessoal, ou seja, a função significativa dos termos, que é possivel, segundo Ockham, se pensar a realidade.

Ockham sustenta firmemente que o universal é um conceito mental, um ato intelectivo; não possui existência fora da alma, ou seja, tudo que é universal predicável de vários, está por sua natureza, na mente. Mas será somente dentro de uma proposição que ele ganhará significação. Isto significa que o universal é expresso como termo que supõe por algo em uma proposição. Ora, se os termos, ou nomes, com que formamos as proposições de que nossa ciência é feita, são signos, ou substitutos, que fazem as vezes na linguagem, dos indivíduos correspondentes"9 vale dizer, então, que eles designam coisas e como tal particulares, contudo estas coisas particulares na mente e que não se encontram dada na realidade, uma vez que é um conceito e não uma coisa sensível, tem uma abrangência universal.

Assim, os termos são fatos "reais" do ponto de vista do significado, enquanto tem um valor simbólico, enquanto indica alguma coisa. Em suma, para evidenciar estes singulares, ele se utiliza dos conceitos, que são significações, estão no lugar dos significados que nomeiam, são suposições pessoais.

Portanto, é de notar, a partir deste texto, que para ele, também a ciência estabelece-se na teoria da suposição. Logo, é importante conhecer a teoria da suposição, para melhor entender a relação entre o objeto da ciência e as coisas sensiveis. A Teoria da suposição desenvolvida por Ockham nos apresenta as diversas maneiras do termo supor, ou seja, ao tentarmos estabelecer a verdade ou falsidade de uma proposição, temos que identificar se a suposição em questão é pessoal, simples ou material.

Por fim, retornando às primeiras questões apresentadas, fica fácil agora a compreensão das mesmas. A ciência, então, é formada de proposições e os termos destas proposições ganham força a partir daquilo de que eles "fazem as vezes" (supõem), ou são aptos a suprir por algo dentro destas proposições. Desta forma, as proposições são objetos científicos. No caso da física, em função do que foi discorrido, ela supõe por coisas naturais. Com efeito, não se faz ciência tendo as coisas sensiveis por objeto, mas através daquilo que elas supõem, ou seja, só pode haver conhecimento das proposições que são as coisas extra-mentais. Neste caso, podese dizer que a ciência resulta do conjunto de proposições, cujos termos supõem pelas coisas naturais, naturalmente em nossa mente.

\section{Bibliografia}

GHISALBERTI, A. Guilherme de Ockham. Tradução de Luís Alberto De Boni, EDIPUCRS, Porto Alegre, 1997 
